
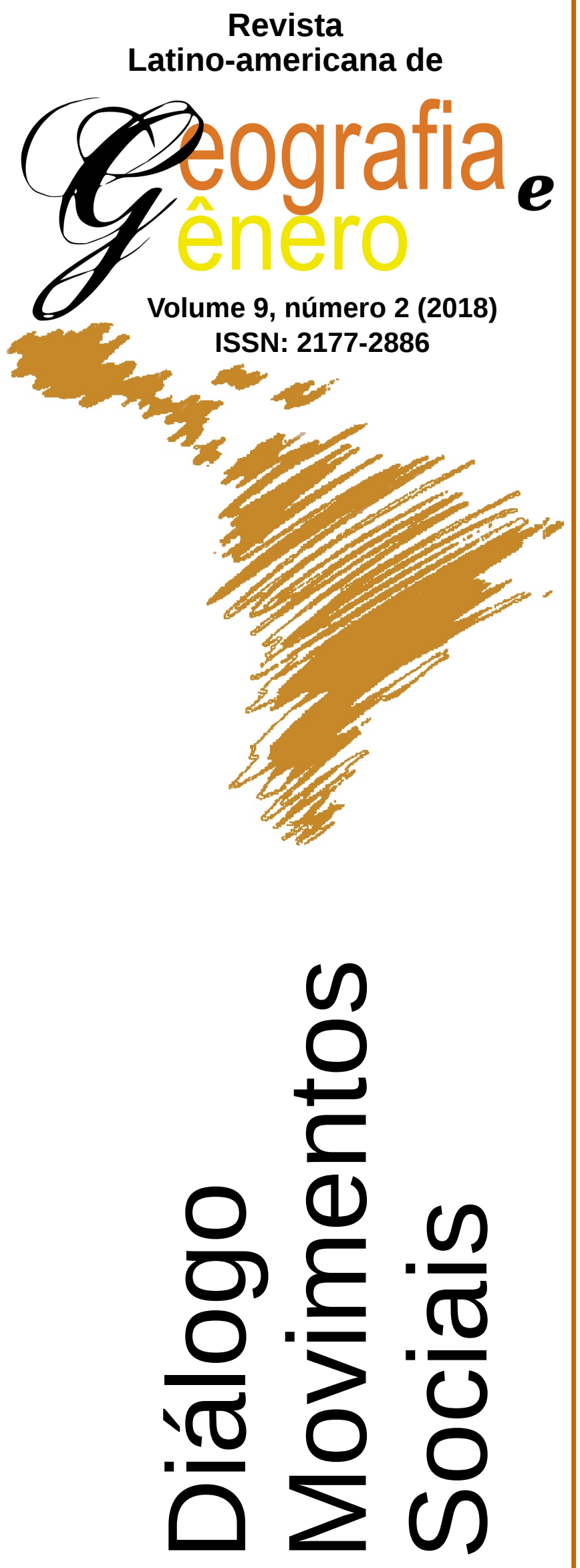

O que Pode (n)um Corpo, o que Cabe Nele - Sabemos o que é um Corpo Travesti?

Lo que Puede (n) un Cuerpo, lo que Cabe em el - ¿Sabemos lo que es un Cuerpo Travesti?

What Can a Body do, What Holds (in) it - Do we Know What a Transvestite Body is?

\section{Adriana Sales}

Secretaria de Estado de Educação de Mato Grosso - SEDUC

Associação Nacional de Travestis e Transexuais I ANTRA - Brasil adriana.salesunesp@gmail.com

\section{Wiliam Siqueira Peres}

Universidade Estadual Paulista "Júlio de Mesquita Filho" - Brasil

pereswiliam@gmail.com

Como citar este artigo:

SALES, Adriana; PERES, Wiliam Siqueira. O que Pode (n)um Corpo, o que Cabe Nele - Sabemos o que é um Corpo Travesti? Revista Latino Americana de Geografia e Gênero, v. 9, n. 2, p. 274-292, 2018. ISSN 2177-2886.

Disponível em:

http://www.revistas2.uepg.br/index.php/rlagg 


\title{
O que Pode (n)um Corpo, o que Cabe Nele - Sabemos o que é um Corpo Travesti?
}

\author{
Lo que Puede (n)un Cuerpo, lo que Cabe em el - ¿Sabemos lo que es un \\ Cuerpo Travesti?
}

\author{
What Can a Body do, What Holds (in) it - Do we Know What a Transvestite \\ Body is?
}

\begin{abstract}
Resumo
Este texto busca estabelecer problematizações acerca das corporalidades travestis, as performances que estes corpos habitam nas relações políticas/culturais/sociais/estéticas e os rompimentos com os padrões biologizantes que se espera para os corpos binarizados. As possibilidades destoantes das vivências trans são os disparadores para ampliarmos os universos de referências sobre o que pode um corpo? O que cabe nele? Quais os dispositivos de resistências e fugas que essas pessoas articulam para garantirem sua manutenção, das vidas potentes e a refuta para as capturas dos discursos que buscam, em muitas vezes, capturar outras vivências que não as esperadas pela sociedade patriarcal e machista; outros meandros e tecnologias que conectem os desejos, necessidades e anseios que necessitam de outras corporalidades para além do macho e fêmea, além do homem X mulher? Logo, mapear os discursos e narrativas das vozes travestis é fator fundante para que possamos garantir os novos saberes tão válidos quanto qualquer outro.
\end{abstract}

Palavras-Chave: corpo travesti; corporalidades trans; corpos dissidentes.

\section{Resumen}

Este texto busca establecer problemáticas acerca de las corporalidades travestis, las performances que este cuerpo habita en las relaciones política/culturales/sociales/estéticas y como estos rompen con los patrones biologizantes que se espera para los cuerpos binarizados. Las posibilidades disonantes de las vivencias trans son los disparadores para ampliarnos los universos de referencias sobre ¿lo que puede un cuerpo? ¿lo que cabe en él? Cuales son los dispositivos de resistencia y fuga que esas personas articulan para garantizar su mantención de las vidas potentes y la refutación para la captura de los discursos que buscan, muchas veces, capturar otras vivencias que no son las esperadas por la sociedad patriarcal y machista; otros meandros y tecnologías que conectan los deseos, necesidades y anhelos que necesitan de otras corporalidades que van más allá del macho y la hembra, ¿más allá del hombre $\mathrm{X}$ mujer? Luego, mapear los discurso y narrativas de las voces travestis es un factor fundamental para que podamos garantizar los nuevos saberes tan validos como cualquier otro.

Palabras-Clave: cuerpo travesti; corporalidades trans; cuerpos disidentes.

Adriana Sales, Wiliam Siqueira Peres

Revista Latino-americana de Geografia e Gênero, Ponta Grossa, v. 9, n. 2, p. 274 - 292, ago. / dez. 2018. 


\begin{abstract}
This text aims to problematize transvestite corporalities, the performances that these bodies inhabit in the political/cultural/social/aesthetic relations, and their disruptions with the biologizing standards that are expected for binarized bodies. Are the possibilities of trans experience different from the ones we have developed in order to expand the universes of references about what a body can be? What fits to it? Which devices of resistance and flight do these people articulate in order to guarantee their maintenance of potent lives and to refuse the catches of the discourses that seek, most of the time, to capture other experiences than those expected by the patriarchal and male chauvinist society; other meanders and technologies that connect the desires, necessities and longings that need other corporalities beyond male and female, in addition to that of male $\mathrm{X}$ woman? Therefore, mapping the speeches and narratives of transvestite voices is a founding factor so that we can guarantee voices that hold a knowledge that is as valid as any other.
\end{abstract}

Keywords: Transvestite bodies; Trans corporalities; Dissident bodies.

\title{
Desenvolvimento
}

Apresentar qualquer defesa, qualquer conceituação, acerca de corporalidades travestis é, com certeza, arbitrário, porém, problematizar algumas possibilidades destes corpos fluídos e que vibram a todo tempo é nossa intenção, logo o que se entende por arbitrário, para nós, é resistência.

Os corpos travestis, que transitam na sociedade (nos territórios), trazem consigo os processos transbordantes que destoam do que se espera nos padrões hegemônicos, então, suas construções, atravessadas pelas recusas das pessoas nas variadas relações, podem causar sofrimentos irreversíveis para elas, porém, o que marcamos aqui, são as corporalidades que resistiram (sobreviveram) a todo processo violento e marcam porque as travestis eleitas para este mapeamento, são lideranças nacionais, no que tange ao movimento social organizado no Brasil.

Esta proposta de problematização emergiu após pesquisa de doutoramento concluída no ano de 2018, cujo objetivo geral foi trazer a história do movimento de travestis brasileiras desde o ano de 1995, eleger treze lideranças deste coletivo nacional das cinco regiões do país e explorar as questões de gêneros, sexualidades, corporalidades nos espaços (territórios) escolares.

São geografias mapeadas, partindo de estudos feministas sobre gêneros, reconhecidos por serem avanços na história da humanidade, que garantem que "[...] as pluralidades de abordagens nesse campo de saber são expressões de sua riqueza teórico-metodológica, e se convertem também em energias que renovam os debates e o avanço científico [...]" (SILVA, 2009, p. 50).

Após a pesquisa concluída recortamos esta discussão acerca das corporalidades travestis, os possíveis modos de vidas, estilísticas de existências e os modos operantes que cada participante do trabalho nos apontou enquanto resistências diante as muitas violências físicas e psicossociais que as mesmas enfrentaram e enfrentam para serem como querem ser, com seus corpos subversivos.

Importante salientar que os nomes sociais de cada liderança nacional foram mantidos por escolha e sugestão das mesmas, fato aprovado pelo Comitê de 
Ética da referida instituição que outorgou a pesquisa e sua conclusão, pois compreendemos que tal posição de manutenção tem intenção política no enfrentamento de produções que sempre utilizaram das travestis, suas vidas e suas corporalidades como objetos de pesquisa, mas que, quase sempre, não dão os créditos reais às mais importantes pessoas destas produções de conhecimentos.

São corpos resistentes, que utilizam ferramentas inimagináveis às percepções de corporalidades binárias biologizadas, a partir de pênis e vagina, pois, os corpos travestis flutuam, a partir de suas genitálias (de macho) e nas tecnologias possíveis (quase impossíveis) para garantir suas feminilidades desejadas. Dialogando com os escritos de Suely Rolnik (2014, p. 47), são corpos vibráteis;

[...] isso se considerarmos o corpo em seu potencial expressivo, sua invisível vibração, suas singularidades afetivas. Em suma, se considerarmos o corpo sem órgãos e não o corpo orgânico, com seus significados a priori: corpo que vê e é visto pelo olho nu.

Podemos perceber estas tecnologias e resistências de criação das corporalidades, que são fluidas, nos extratos que seguem. Os referidos extratos foram mapeados, transcritos e alocados em subgrupos por temas no decorrer das entrevistas e encontros com as participantes da pesquisa. Esses dados foram atravessados pela perspectiva cartográfica que deu ferramentas para que pudéssemos ter liberdade nas relações e proximidade com as mesmas, visto que uma das autoras deste artigo faz parte do movimento travesti brasileiro e atua diretamente na ANTRA ${ }^{1}$.

As perspectivas cartográficas reafirmam as posições da e na pesquisa, porque todas as relações e momentos vividos nos percursos do trabalho levaram em conta as processualidades de cada momento, que se somam numa ética 'transdutiva' e 'transversal', pois '“...] sujeito(a) e objeto de pesquisa se apresentam como duas dimensões distintas, porém inseparáveis, de uma mesma realidade reticular [...]" (ESCÓSSIA; TEDESCO, 2009, p. 106).

Ao preconizar os ecos dessas vozes, para além dos resultados das relações, que se somam às intencionalidades da pesquisadora travesti, nesses diálogos, marcamos a cartografia trazendo latentes aspectos de engajamento político para com as produções científicas na atualidade, pois,

Garantir a participação dos sujeitos/sujeitas envolvidas na pesquisa cartográfica significa fazer valer o protagonismo do objeto e a sua inclusão ativa no processo de produção de conhecimento, o que por si só intervém na realizada, já que desestabiliza os modos de organização do conhecimento e das instituições marcados pela hierarquia dos diferentes e pelo corporativismo dos iguais (KASTRUP; PASSOS, 2013, p. 270).

1 Associação Nacional de Travestis e Transexuais. Criada no ano de 2014, aglomerando cerca de 114 instituições afiliadas. 


Estas estratégias de pesquisa caracterizam-se como posicionamentos
estéticos, enquanto cartografia, ao reforçar os variados deslocamentos que
"[...] viabilizam o acesso ao plano de transformação da vida, em vez de
funcionar de modo mecânico, automático, no já dado sistema fechado
sujeito(a)-objeto" (SADE; KASTRUP, 2011, p. 144).
Toda essa tessitura foi atravessada por vários marcadores de estigmas como
raça/cor e classe, pois essas pessoas utilizam as contestações, as resistências,
para a manutenção das vidas. De acordo com Peter Pelbart (2003), ao
problematizar "A comunidade dos sem comunidade", essas resistências são
estratégias em que composições e recomposições de singularidades têm lugar.
São confluências, quase que hegemônicas, nos contextos históricos das
vivências travestis no Brasil, que apontam a emergência de reorganizarmos as
significações acerca dos corpos possíveis e suas potencialidades de vida. Pois,
ao pinçarmos os discursos abaixo:
[...] mas ela era muito bonita, trabalhava de espartilho, nua na casa
da cultura, com próteses de silicone, com peito de prótese, ter prótese
naquela época era um status que poucas tinham, então ela não tinha
que olhar pra mim e nem Bruna (Entrevista realizada com: Keila
Simpson).
Através de hormônios, através de amigas que me indicavam os
hormônios a usar, tomava os anticoncepcionais da minha mãe, eram
o anasicleans, bombas de hormônio na época e essas amigas,
Fernanda, Veronica, Diana, Rosangela, todas me indicavam, falavam
que não me arrependeria mais tarde, etc e tal e como eu não queria
ser prostituta, elas todas se prostituiam, eu achava que uma coisa
levava a outra, eu dizia então que travesti tudo bem, puta não! E eu
comecei a tomar hormônios, assim do nada. Para mim era como
balas, então foi assim, aos doze anos, sem nenhuma, a não ser
conselho de amigas, não teve aconselhamento médico, nada, como a
grande maioria não tem (Entrevista realizada com: Indianara
Siqueira).

De acordo com os extratos acima, pode-se marcar alguns elementos que pontuam as estratégias de reconhecimento dos universos femininos e masculinos, que vão constituindo as corporalidades travestis e como são reproduzidas nas várias regiões do país, em seus territórios geopolíticos com suas diversidades.

Estes elementos vão se repetindo, obviamente, de modos singulares, em cada experimentação travesti, mas que se entrecruzam nas vivências destas pessoas e operam, quase que como regras, para se reconhecerem no universo destes corpos (im) possíveis e (in) vivíveis.

Mesmo que estes processos acarretem condições de sofrimentos, dores, dissabores, decepções, violências e estigmatizações para com as defesas e marcas que se posicionam, politicamente, na construção destes corpos. Como nos mostram Symmy e Indianara: 
[...] desde criança percebia num espaço que era um espaço que meu corpo não abarcava, né. Eu me identificava muito mais do que aquele meu corpo era, só que eu não tinha noção disso (Entrevista realizada com: Symmy Larrat).

Um corpo travesti, é aquele corpo que pode ser violentando, que não tem direitos, que ao mesmo tempo essa falta de direito nos dá de não seguir regras, o corpo travesti, nos dá direito de não seguir as regras cis gêneros, porque a sociedade cis heteronormativa, esse corpo, pra violentá-lo, vai libertando também outras pessoas que vão usando essa maneira de se vestir, essa maneira de viver, então ter um corpo travesti, é ter um corpo que não se adequa a sociedade, mas essa definição também te dá a oportunidade de fazer tuas escolha. É então esse corpo, é um corpo mulher- travesti, é um corpo homem travestido, que corpo é esse, toda essa problemática causa nos outros que para nós é tão natural, transexuais, travestis, transgêneros, pessoas não binarias, não conforme, é natural pra elas existirem, é pra outras pessoas que não é natural, mas pras pessoas que existem dessa forma, é natural, simples, o problema está pros outros, não pro nosso, então você existe, independente dos outros. (entrevista realizada com: Indianara Siqueira)

O desejo por um corpo que esteja de acordo com seu desejo e suas expectativas, mesmo que no enfrentamento pelas suas sobrevivências, possibilitam a inserção (o uso) de ferramentas (tecnologias) que vão performatizando suas constituições corpóreas e afetando as normas dos (nos) corpos, pois, os afetos marcam os corpos vibráteis e seus fluxos.

Tais tecnologias, como os usos de silicone industrial, uso de hormônios femininos e implantes de próteses mamárias, foram, no desvelar da história destas pessoas, marcando-se como elementos fundamentais para 0 autorreconhecimento, a validação de suas corporalidades por suas parceiras e a realização pessoal em se reconhecer, de modo feliz, suas corporalidades readequadas (reorganizadas/ressignificadas).

Os afetos, os desejos, exemplificados, abaixo, por Melissa, operam de modo a contemplarem o que se quer fazer com essas corporalidades e de como estas posições políticas dos corpos/afetação coadunam-se para suas expressões de vida e identidades políticas coletivas.

Então eu pude deitar e colocar o silicone, eu não aguentei e ai eu desmaiei e isso foi aos dezenove anos e ai eu tive uma pressão da cultura trans de que eu tinha que colocar o silicone, e então como eu quase morri de colocar silicone. Ai a bombadeira me disse, não, você é tão bonita né, toma hormônio e bota prótese! Ai eu fiquei, toma hormônio e bota prótese, toma hormônio e bota prótese! (Entrevista realizada com: Melissa Campos)

Estes dispositivos discursivos correspondem aos seus anseios singulares (rompendo aos binarismos universais biologizantes). Pois, os enquadramentos 
binários, partindo de aspectos morais religiosos e sexuais reprodutivos, tentam determinar, exaustivamente, as identidades fixas, distintas, opostas, porém, não flexíveis (BUTLER, 2015).

E é, justamente este enquadramento, que as travestis no Brasil, rompem com suas corporalidades, que transitam entre as feminilidades e masculinidades, se posicionando não num outro corpo não binário, mas em corporalidades femininas, em expressões de gêneros 'femininos'", mas que marca a resistência aos corpos fixos, rígidos, que não contemplam suas necessidades e desejos.

Estes corpos travestis é a materialização das tecnologias corporais em Donna Haraway (1995 e 2009), as resistências e os quadros de guerra em Judith Butler (2003 e 2015), as manifestações sexuais de Paul B. Preciado (2014), e as outras tantas defesas pela vida, na teoria, mas que se concretiza e se expressa nas corporalidades das travestilidades brasileiras. As travestis através de seus corpos resistem aos poderes hegemônicos na prática enquanto os acadêmicos o fazem na teoria.

Estes elementos todos reafirmam que tudo é mutável, possível, reorganizável e que as corporalidades travestis utilizam-se dos muitos recursos tecnológicos (maquínicos) para garantirem que suas existências sejam possíveis, viáveis e felizes (estilísticas de viver) (exitosas).

Seguindo com os extratos,

[...] é um corpo construído a base de hormônios, a base de silicone, a base de muito sofrimento, de muita "porrada" social pra construir esse corpo. É esse corpo que é modelado ao meu jeito, a minha forma, porque o corpo de uma travesti, ela não tem uma forma, ela não tem um formato único, nós não somos bonecas que somos fabricadas em série, o formato anatômico não é o mais importante, mas é o corpo que é construído, e que esse corpo vem falar pra sociedade que nós somos mulheres, que nós temos esse corpo feminino que é o atrativo que também faz com que no desejo sexual dos homens, este seja um dos atrativos, de ter nascido num corpo biologicamente masculino e vivenciar essa feminilidade vinte e quatro horas (Entrevista realizada com: Fernanda Benvenutty).

Um corpo travesti pra mim, eu acho que me completa, o que minha cabeça diz que eu sou, eu não seria, se eu tivesse como meu corpo de Jacson, e me vestindo como Jaqueline, minha mente pediria mais, a minha mente pediria mais, eu precisava ter formas pra me sentir Jaqueline, eu precisava ter seios pra me sentir Jaqueline, eu precisava ter quadris pra me sentir Jaqueline, porque Jaqueline pra mim não era um personagem (Entrevista realizada com: Jaqueline Brasil).

Diante aos discursos acima, muitas são as ferramentas (estratégias/tecnologias) utilizadas pelas travestis e esses processos desejantes podem ser lidos como táticas de sobrevivência, táticas de guerrilhas, fuga dos sofrimentos e modos de garantirem que suas identidades políticas sejam 
respeitadas.

Essas ferramentas podem ser lidas como dispositivos das travestilidades, trazendo dados da cultura, produção dos dados desejados, de afetos que marcam nos processos corporais, seus investimentos, acréscimos e decréscimos no/do corpo o que se quer adequar para um bem-estar.

As linhas que vão tecendo estes processos corporais, glamour, estética, enquadramento cultural no universo travesti, para serem reconhecidas entre seus pares, dinamizam um entroncamento que linka vários fios, vários elementos que confluem e não tem obrigatoriedade de nenhum nivelamento. Ao contrário, pode (deve) estar sempre em movimento, aberto, fluído: um rizoma (DELEUZE; GUATARRI, 1995).

Os meandros que vão forjando estes corpos demandam retomadas para o reconhecimento de performances possíveis, vidas vivíveis e que importam, pois estão lá (na sociedade/nos cotidianos) e continuarão existindo (resistindo).

Seguindo com os discursos:

Ai eu ia fazer o silicone industrial, comprei um litro de silicone na época, que também quando eu era mais jovem, é que prostitui também, em São Paulo, tinha uma cafetina, chamada Tuca, na época, e lá também fazia aplicação de silicone, eu comprei um litro, mas quando eu fui colocar, eu ia colocar meio em cada lado, cada lado no quadril, mas eu cheguei a desmaiar, porque eu sou muito mole pra dor, coloquei um copo em cada lado, só não desisti, pra não ficar com defeito, mas realmente, eu acho que esse silicone industrial, não é recomendável pra ninguém, porque quando as pessoas chegam numa certa idade, ele empedra no corpo e causa os efeitos e alguns defeitos. É verdade, vai ficando assim... (Entrevista realizada com: Cris De Madri).

Então eu meio que fui rato de laboratório mesmo na hormonioterapia, mas ai eu elegi a perlutan que é a de todas, que eu acho que é nacional, né. E dali eu tomei muita perlutan, e agora já faz dois anos que eu não tomo mais hormônio, porque agora eu quero ver qual o é o meu corpo aos quarenta né. Eu quis desintoxicar todo esse corpo e trazer uma outra forma de ser mulher. Essa mistura mesmo do masculino com o feminino né. Trabalhar essa androgenia, sem a pressão da hormonioterapia. (Entrevista realizada com: Melissa Campos)

O desejo em ser reconhecida no gênero feminino é condição fundamental para garantia de sua felicidade. Logo, os riscos que elas enfrentam, diariamente, sempre, para elas (nós), vale a pena, porque, não há possibilidade de apresentar as travestilidades sem todos os aparatos, inclusive corporais, que acreditam marcar essas feminilidades e seus modos de viver.

Há uma necessidade urgente em revermos qual é o modelo de sociedade viável e quais corpos cabem nele, pois, "a mudança atual de status do corpo, no âmbito do discurso social, engendra o prazer de ser quem se é sem que interfiram no juízo de si os modelos estéticos em vigor, a idade, a sedução, as 
deficiências eventuais, etc.” (BRETON, 2013, p. 220).

Neste sentido, ser uma travesti, negra, cadeirante, obesa, idosa, periférica, vivendo com o HIV, dá o tom do quão urgente é esta questão defendida e como as produções de ciências, como a psicologia e educação, precisam pautar as possibilidades e garantia das vidas. Pois é impossível problematizar sobre sem perceber as complexidades de tais composições, porque inauguram as estéticas travestis.

Apresentar os efeitos das tecnologias nos corpos, inserir instrumentos que possam causar suas mortes, é marca intrigante das travestis. Seus corpos são elaborados com estas ferramentas, porque são os dispositivos possíveis à disposição de suas sobrevivências cotidianas, garantindo a elas, somente a elas, a tutela de suas corporalidades. Ou seja, cabe às travestis de direito e somente a elas falarem de si, definirem-se por si mesmas e não ser definidas por poderes moralistas e essencialistas estranhos e externos a suas vidas.

As novas possibilidades de outros modos de circular no mundo é condição para suas existências e a reconfiguração das corporalidades vai agindo, processualmente, em cada momento histórico deste coletivo, sendo estratégias para validar suas expressões de gênero travesti.

Ao defender (fazer) os usos de silicone industrial, implante de próteses, uso de hormônios femininos, depilações definitivas a laser, implantes de cabelos artificiais, entre outras tantas possibilidades, denotam as muitas variáveis de existir/resistir na contemporaneidade, sempre pautadas, historicamente, nos processos temporais que esta população viveu e vive. Inventa e sustenta novas feminilidades, assim como, novas tecnologias corporais.

As muitas subjetividades, que atravessam essas corporalidades, são marcas e posições políticas muito bem costuradas por estas lideranças, que articularam toda a história do movimento social coletivo e estão nos dando (para a academia), de 'bandeja', posições de vida que são mais que viáveis.

Estes muitos corpos são resultados de muitas experimentações de violências macro e micropolíticas, que vão resistindo na sociedade brasileira e corroboram com os modos de subjetivação que constituem as pessoas. Assim, não podemos mais, não temos mais tempo, para permanecermos com os discursos e práticas acerca de corpos a partir de genitálias, pois há urgência em escaparmos das perspectivas higienistas, que se reduzem ao binarismo biologizante.

A biologia não é o final, não é tudo. A biologia pode ser o início, porém nunca o produto final, como sempre afirmava, em seus muitos discursos acalorados, nossa companheira Lohanna Berkins ${ }^{2}$. Complementando, em Haraway (2004, p. 244-245),

[...] ao invés disso, relatos políticos de corporificações construídas como as teorias feministas de subjetividades marcadas por gênero e raça, têm, necessariamente, de levar em conta, afirmativa e criticamente, subjetividades sociais emergentes, diferenciadas, autorrepresentadas, contraditórias, com suas exigências de ação,

2 Ativista argentina com grande destaque e reconhecimento em sua atuação combatente por leis e projetos para população trans. Falecida no dia 05 de fevereiro de 2016. 
conhecimento e crença.

Os marcadores sociais que compõem estas subjetividades, marcadas nas estéticas corporais desmontam o legível, ou o que se quer reconhecer como legítimo. Trazem à tona, outras configurações que, muitas das vezes, se tornam insuportáveis para as pessoas, que se limita a reconhecer o óbvio, o básico, o natural, o biológico, o que cabe e não cabe para a sociedade heterossexista e machista.

Os discursos que vão buscando perpetuar seu poder são colocados em xeque para os novos discursos (marginais) que revelam, quase que como milagre, certas verdades humanas e trazem o que não é dito, nem pronunciado, à tona, emergindo da mais profunda recusa social, suas existências felizes e possíveis (reais) e que não podem mais ser mascaradas (FOUCAULT, 1996).

Ter um corpo feminino, com elementos bem contundentes (seios enormes, quadris enormes, bochechas torneadas, cabelos longos, do que se confere, no ocidente, como 'do feminino', e possuindo elementos de macho, como pênis e pelos pelo corpo), se torna inaceitável para as possibilidades dos corpos higienizados nos parâmetros universais binários.

As travestis processam esta elaboração de modo a romper com tudo isso. Implodem as perspectivas tradicionais e transitam com o que seria impossível: uma figura feminina, um corpo ambíguo, com pênis, porém exigindo sua identidade política, não de mulher, mas de travesti, logo, feminina.

Seguindo com os extratos:

[...] dessa postura que já mostrava nós, que não éramos rapazes, tampouco de peito, éramos figuras femininas que tínhamos peito, que tínhamos quadril, que tínhamos tudo, eu compreendia tudo aquilo, mas eu também não determinava quem eu Era" (Entrevista Realizada Com: Indianara Siqueira)

[...] eu tenho dois litros de silicone industrial, né, que ele faz os moldes do corpo, porque a estrutura masculina é bem diferente da feminina. (Entrevista realizada com: Daniela Veiga)

As travestis apresentam seus corpos sempre na disputa do que se é regulável. Elas são a contestação do óbvio. Elas têm suas tutelas corporais mesmo sem a atestação da sociedade brasileira, pois, elas constroem, performam, articulam e impõem suas corporalidades como elas (nós) querem para serem felizes e satisfeitas em seus gêneros femininos.

Elas apresentam corpos que implodem as identidades fixas biologizantes ao apresentarem perspectivas queers nas suas elaborações e processos de subjetivação. Conseguem, com suas posições de vidas, na maioria das vezes, denunciar as capturas binárias e nos apontam quão plural e diversa é (pode) a sociedade contemporânea brasileira. Como notamos nos extratos de Luana e Taís, que seguem:

E realmente a feminilidade, ser feminina no masculino é o mistério, é a sedução, é essa questão que vende o produto, mas não entrega, que 
não é enganar e roubar ninguém, não, até porque essa época já passou. (Entrevista realizada com: Luana Muniz)

Hoje eu estou bem com meu pênis, mas se eu tiver que adequar ele amanhã, eu vou continuar bem, porque hoje eu consigo me reconhecer como Taís, e o meu pênis hoje pra mim, é como se fosse um dedo a mais na minha mão, se eu tivesse, foi como se minha orelha fosse grande e eu quisesse ela pequena, então eu não tenho problema com a minha sexualidade hoje, tanto pelas minhas questões pessoais, como as minhas questões de relacionamento que eu já tive, entende. (Entrevista realizada com: Taís Diniz Souza)

Estas pessoas trazem em seus corpos o que mais tem de abjeto na sociedade: um falo num corpo feminino; um pênis num corpo que é reconhecido como de mulher; uma mulher exagerada (a priori), que exala os elementos do que se é reconhecido para o feminino; seios fartos; bunda farta; 'pau' farto.

As travestis conseguem desterritorializar os corpos esperados para uma provável biologia e reterritorializar outras significações para estes corpos, pois esta reterritorialização permitem "processos que se produzem e aparecem nas multiplicidades. Não supõem nenhuma unidade, não entram em nenhuma totalidade e tampouco remetem a um sujeito" (DELEUZE; GUATTARI, 1995, p. 8).

O que menos se espera, na relação com a sociedade, é que suas posições políticas sejam fartas e que elas articulem para que seu coletivo tenha empoderamentos para perpetuar a luta (resistência) por direitos de ir e vir, apontado por Symmy e Melissa:

E que ele é tão ou mais cruel que os outros armários, né, porque você fica assumindo várias identidades até chegar na identidade que você identifica pra si, então, é naquele momento em que eu vesti a minha primeira roupa feminina pra sair durante o dia, e eu era, fazia pista a noite, era voluntária no centro de referência da minha cidade que ai naquele dia eu me reconheci, como Symy Larrat. (Entrevista realizada com: Symmy Larrat)

Eu acho que é porque é um corpo que é único né, não tem como adequá-lo e nem encaixá-lo na caixinha que é a sociedade, que é a caixinha do homem, que é a caixinha da mulher, sabe. A gente não entende qual é o lugar da gente inicialmente, mas a gente sabe que aqueles dois lugares que existem, que é o do homem e o da mulher não é nosso. (Entrevista realizada com: Melissa Campos)

As resistências atravessam os campos do imaginário para garantir que suas histórias (corpos) possam transitar de modo tranquilo nestas relações sociais transfóbicas e falocêntricas, porque elas têm falo, tem pau, e querem marcar que se é possível ser feminina, possuindo esta 'maldita/bendita' ferramenta; que muitos homens 'héteros' tanto procuram e gostam.

Adriana Sales, Wiliam Siqueira Peres 
As variadas marcas sociais vão constituindo o que é consenso entre estas vidas e estes corpos, estigmatizados, vão transbordando das capturas rígidas do que se espera como 'normal', visto que;

Os indicadores sociais mais significativos de uma "liberação" medida a partir do corpo seriam mesmo a integração como parceira integral no campo da comunicação (parceiros são marcados por estigmas) da pessoa idosa, ou tendo uma deficiência, da pessoa obesa ou portadora de cicatrizes (BRETON, 2013, p. 220).

Neste sentido, os estratos nos atestam:

Eu costumo brincar que, como meu escritório, é meu corpo, eu posso armar ele em qualquer espaço, e sempre tem clientes passando, disponíveis pra isso. (Entrevista realizada com: Luana Muniz)

A definição se passa através também de modificações corpóreas com hormônios, silicone injetável, cirurgias e etc e tal, para a aparência feminina, foi incrementada a uma definição do mundo cis hetero normativo. E como não são definições que fui eu que fiz, eu não me sinto contemplada pela definição, pessoa, eu passei a dizer que eu era uma mulher normal de peito e de peito, mas o que é ser mulher e ser normal nessa sociedade? Mas eu sou pessoa, de peito e de pau, mas se for para escolher, se eu tiver que escolher uma palavra como definição eu escolho travesti pela marginalidade da palavra, pela força da palavra, pelo politico da palavra, que já abre caminhos também, então, não fica aquela coisa limpinha e higienista, então eu prefiro essa palavra pela força que ela tem. Travesti e puta. (Entrevista realizada com: Indianara Siqueira)

Os muitos discursos, que atravessam os extratos acima, acerca das corporalidades, já na própria escolha de um nome 'identificável' para sua existência, estigmatizam essas pessoas e capturam-nas, em certos momentos, seus próprios caminhos para a elaboração de seus processos corporais: podendo ser em processos abertos, flexíveis, desmontável, reversível, etc (DELEUZE; GUATTARI, 1995).

E, é, já no próprio discurso seletivo sobre os corpos, o que pode nele, o que cabe nele, e as possibilidades ou não de escolhas por seus nomes sociais, nomes que não mais os escolhidos e registrados por suas famílias, já após o parto, ou mesmo antes dele, que são reduzidos nos disciplinamentos dos discursos e controles dos corpos. Para Foucault (1996, p. 33), "no interior de seus limites, cada disciplina reconhece proposições verdadeiras e falsas; mas ela repele, para fora de suas margens, toda uma teratologia do saber".

Ao recusar estes disciplinamentos e controles, as travestis, com seus corpos vibráteis, em processo, enfrentam estes dispositivos de controle com os conhecimentos, que aprendem uma com as outras, como observamos nos discursos de Melissa e Jaqueline. 
É um corpo que não limita, que não cede a limitações, se supera, se regenera, sabe. É um corpo na resistência e é isso que eu mostro trabalhando de um elemento para outro, sabe. (Entrevista realizada com: Melissa Campos)

Se eu tivesse seios, se eu não tivesse o corpo, que por mais que ele está da forma que está, eu aprendi a gostar dele da forma que está, aprendi a respeitá-lo, que a gente tem que aprender a respeitar o nosso corpo, gostar dele do jeito que ele é. (Entrevista realizada com: Jaqueline Brasil)

Se não é acessível qualquer política de saúde que correspondam com seus anseios corporais, elas vão para o que se reconhece como ilícito ou não recomendável, porém, são as saídas possíveis que elas, de modo muito sagaz, encontram nestes novos saberes e conhecimentos.

Estas reconfigurações dos usos de variadas tecnologias dão pistas das muitas necessidades que estas pessoas têm, denunciam a precariedade da saúde pública no Brasil e, mais uma vez, apresentam outras formas de conhecimentos possibilitados (estrategicamente, encontrados nas resistências) pelas suas experiências de vidas.

Esses conhecimentos registrados pelos atos discursivos monitorados, cotidianamente, nas histórias das relações capturam (enclausuram) certos corpos. São policiados, vigiados, para Foucault (1984), nos limites das regras estabelecidas pelos contratos socioculturais e políticos na contemporaneidade, porém que escapam, muitas das vezes, de acordo com as histórias deste coletivo, as tais tentativas de aprisionamento.

Ao observarmos o discurso de Cris de Madri:

Nos anos noventa, eu acho, que tinha aquelas travestis cheias de silicone no quadril, aquelas bundas enormes, siliconadas, chamava muito a atenção, na época também, os peitos chamava muito a atenção dos homens, hoje não, hoje já é uma coisa normal, as travestis não querem mais encher aquele corpão de silicone, coloca um pouco pra dar uma visual... mas o corpo mais assim, normal, não como aqueles corpos que eu vi aberrantes, como eu já vi, e tem algumas ainda, ou no nosso... nesses anos, mas só que isso veio de anos atrás, que algumas nem faz, porque pode tirar, porque, é eu mesmo, sou magra, assim, meu corpo, não tenho ânsia de colocar silicone, mas porque eu te falei, eu sou muito mole pra dor. (Entrevista realizada com: Cris De Madri)

Podemos constatar que novas corporalidades não cabem nesses contratos e nas novas configurações dos gêneros, das práticas sexuais/desejantes e das estéticas, que borram os binarismos, ou mesmo, as nuances apenas femininas e/ou masculinas, pois, "O corpo não está hoje liberado senão de maneira fragmentada, cindida, do cotidiano" (BRETON, 2013, p. 220).

Aos discursos, que escapam destes determinismos desqualificados, sobram os estigmas que ferem os contratos das proibições. As instituições poderosas 
nestas sociedades, como a escola (academia), por exemplo, utilizam-se destas estigmatizações discursivas para marcarem seus espaços e instrumentalizam certas apropriações políticas dos discursos para manutenção canônica dos corpos biologizados universais. Para Foucault, "[...] todo sistema de educação é uma maneira política de manter ou de modificar a apropriação dos discursos, como os saberes e os poderes que eles trazem consigo [...]" (1996, p. 44).

Os processos desejantes fluídos das travestilidades batalham, cotidianamente, para sobreviver às tentativas de regulação e higienização dos corpos e das sexualidades. E, ao disparar novas estéticas de gêneros políticos, sociais e culturais, clamam novos diálogos e produções de conhecimentos, que contemplem essas pessoas, pois não há mais como escapar destas discussões e novos discursos são necessários.

Novos discursos irradiarão modelos de sociedade, que agreguem estas pessoas de maneira positivada e sempre inquietarão outras emergências para garantia das equidades de direitos para vida.

Os discursos imperativos, de ordem disciplinar, mesmo nos processos de formação escolar, com fortes poderes de policiamentos, deslocam-se nas relações de resistências, capturam as emergentes corporalidades, usando-se de procedimentos verbais para que os discursos sejam bem recebidos, reconhecidos, como padrões para estas sociedades. E, corroborando com Foucault (1996, p. 59),

De sorte que o tênue deslocamento que se propõe praticar na história das ideias e que consiste em tratar, não das representações que pode haver por trás dos discursos, mas dos discursos como séries regulares e distintas de acontecimentos, este tênue deslocamento, temo reconhecer nele como que uma pequena (e talvez odiosa) engrenagem que permite introduzir na raiz do pensamento o acaso, o descontínuo e a materialidade.

Seguindo com os estratos, registramos mais ilustrações sobre as corporalidades travestis:

Eu me vejo fora desse processo, eu acho que meu corpo é como ele é, e eu não sou mais ou menos mulher por conta disso, e se a minha relação com meu corpo é mais uma relação, é menos identitária nesse processo da lógica machista, e mais uma questão de conhecimento, de atuação, conhecimento pra tudo, eu conheço meu corpo pra saber onde eu posso ter prazer, eu conheço meu corpo pra saber onde ele tá mais ruim que eu preciso procurar uma ajuda de saúde, eu conheço meu corpo pra saber... então eu vou me conhecendo nesse sentido. (Entrevista realizada com: Symmy Larrat)

Para construir esse corpo lá no passado, era um corpo que era construído a duras penas. A gente tomava, por exemplo, eu tomava muitos comprimidos de hormônio para desenvolver seios, pra desenvolver formas no meu corpo, femininas, e depois eu tive que passar pela mão da bombadeira, passar pela mão da aplicação do 
silicone, sofri as dores do silicone ser injetado pra ganhar, pra fazer a forma do corpo que eu queria e que pra mim me dava prazer, porque eu construí o meu corpo, não foi pra dar prazer pros os outros, foi pra me satisfazer, foi pra me auto realizar, então é... O sofrimento vem daí, da falta de técnicas menos doloridas, menos sofridas e menos agressivas para o meu corpo, pra construir esse corpo que é o corpo que eu construí pra mim, é o corpo que eu tenho, é o corpo que eu me apresento socialmente, é o corpo que eu vivencio essa travestilidade... (Entrevista realizada com: Fernanda Benvenutty)

As produções discursivas, nos extratos acima, e os conhecimentos elaborados pelas escolas, por exemplo, tomando as atualidades brasileiras, são atravessadas pelas posições políticas de dominação, que negam as processualidades fluídas dos corpos, dos sexos, dos gêneros e alocam as travestilidades sempre vigiadas pelas normas aceitáveis.

Mas, que corporalidades travestis seriam mais passáveis (verbo passar) ou passíveis/aceitas diante dos olhos normativos?

Se os discursos produzidos por certas travestis estão de acordo com feminilidades universais, elas até podem circular em determinados espaços, tempos e linguagens, desde que se coloquem discretamente em seus devidos lugares.

Precisam ser discretas, delicadas, sem pelos nos corpos, atuando em profissões menos rentáveis e submissas nos lugares reconhecidos como sociáveis (shoppings, igrejas, comércio, etc.). Limitam-se (são limitadas) em atuar apenas enquanto 'putas', devem ser dominadoras, seios enormes, pênis dotados, roupas sedutoras, entre outros quesitos, que não são atribuídos às mulheres limpinhas, recatadas e do lar.

Seguindo com a fala de Taís:

Eu acho o que atrapalha não é corpo. O que atrapalhava era o meu nome que não condizia com meu corpo. Porque eu ia fazer uma entrevista de trabalho e a pessoa se encanta comigo, porque eu sou uma pessoa comunicativa, eu dialogo, eu tenho uma experiência boa no curriculum da época da minha formação, eu fiz muito estágio, eu fiz muitos estudos. O problema é que quando olhava para mim, e olhava pro meu $R G$ eu não sei se a pessoa não sabia lidar com aquela questão, eu não sei se ela ia achar que vai ser um problema eu pensar no banheiro, vai ser um problema eu pensar no crachá, então eu não vou ficar com ele ou com ela, entende, eu não sei o que se passava. (Entrevista realizada com: Taís Diniz Souza)

Esses processos todos, de transitar em muitas possibilidades de expressar seus gêneros, nos mostram que as performances atravessam suas vidas e lhe garantem, através de muitas fissuras, processos temporais singulares e que rompem com a rigidez da sexualidade (BUTLER, 1999).

Quando se apresentam rompendo com esses discursos, não mais são aceitas como inteligíveis e suas corporalidades colocadas enquanto marginais. Logo, há demanda urgente em garantir os processos permanentes de subjetivação 
destes corpos.

A regulação dos corpos, a interdição de certas expressões de gêneros e algumas práticas sexuais é estereotipada pelos discursos e as linguagens constituem localizações geopolíticas, de raça, de classe. São dominações sutis, em algumas vezes, que atravessam as relações humanas, institucionais e nas produções dos conhecimentos, que se fundam nas vigílias dos padrões dominantes dos modos certos de pensar, de agir, de produzir corporalidades e estéticas de vidas desviantes.

Os discursos institucionais podem interditar algumas pessoas, alguns grupos e algumas estilísticas das existências, porque são ferramentas biopolíticas que articulam e desarticulam certas sujeitas, como as travestis, tirando delas validades políticas e éticas para as corporalidades e são brutalmente excluídas de toda relação discursiva, via transfobias.

Ao observarmos os discursos de Melissa e Taís:

Uma sexualidade travesti é gozar intensamente e todo o tempo. Eu acho que está a flor da pele, tudo isso na gente! As pessoas sabem que a gente está a flor da pele! Esse erotismo ele existe, apesar de eu trabalhar profissionalmente uma desconstrução, porque eu sou muito erótica e ai eu gosto bastante de trabalhar bastante esse erotismo. Eu não abro mão de poder ser erótica, de tratar a eroticidade. Fico incomodada quando as pessoas querem desconstruir isso em mim. (Entrevista realizada com: Melissa Campos)

A gente sempre coloca o pênis no lugar da nossa cabeça e na verdade não é. A gente tem que colocar a nossa cabeça no lugar do pênis, porque a gente tem que pensar muito e não pensa, entendeu. A gente tem que quebrar esses tabus. A gente tem que ser feliz, en'tendeu, aí o problema se tem pênis ou se não tem, e daí? (Entrevista realizada com: Taís Diniz Souza)

As histórias de vidas de nossas participantes da pesquisa dão o tom de resistências diante a estas interdições, pois as mesmas rompem com as hegemonias discursivas e corporais binárias e lutam pela manutenção e garantia de que seus corpos são possíveis, viáveis e reais.

Os enfrentamentos que elas nos relatam em cada cartografia de vida apontam o modelo de sociedade e feminismo que acreditamos. Uma perspectiva feminina e de gênero que agregue; que seja parceira, que seja pela vida e pelo modelo de sociedade com equidade de direitos nas diferenças e diversidades humanas, porque,

Isto implica o compromisso com a mudança social transformadora, o momento de esperança embutido nas teorias feministas de gênero, e em outros discursos emergentes a respeito da quebra da subjetividade dominadora e na emergência de outros impróprios/não apropriados (HARAWAY, 2004, p. 245).

Logo, as escolas, como uma destas instituições dominadoras, são 
imprudentes, ao trazer, para os cenários das produções dos conhecimentos, sobre essas expressões de gêneros, higienizações binárias e biologizantes, que sempre reproduzem corpos doentes, genitálias sujas e configurações estéticas marginalizadas. Para Ana Godoy (2008, p. 81), "tudo o que escapa a um sistema é visto como perturbação, como ruído, ameaçando sua integridade [...]", inclusive as corporalidades que vibram.

Os discursos imperativos negam qualquer possibilidade de desejos que escapam das amarradas interditas e todas as emergentes sexualidades podem sofrer, angustiar-se, eliminarem-se, mesmo antes de serem banidas das relações respeitosas da vida; interditando e excluindo algumas pessoas e privilegiando outras (FOUCAULT, 2000).

São potentes armas que buscam a domesticação destas sujeitas, que transbordam aos essencialismos, mas que enfrentarão, cada vez, em maior escala, resistências a estes controles, e engendram armadilhas, artimanhas, estratégias, táticas para se fazerem circular de maneira significativa nos novos modelos psicossociais das vidas.

Os sistemas discursivos de exclusão tendem a perder forças quando deparados às experimentações exitosas dos novos modelos e modos de pensar e produzir conhecimentos. São contra discursos que ampliam (implodem) os universos de referências binários.

Alargam-se em outros sistemas, nem melhor nem pior, mas com outros elementos que instituem lógicas não mais marginalizadas, desviantes, pecaminosas e patologizadas, porque, para Deleuze (1976, p. 83), em Nietzsche e a Filosofia, "pensar a vida é ultrapassar os limites fixados pela vida racional para o pensamento".

Expressões humanas que não coincidem mais com os gêneros heteronormativos, machistas, sexistas, xenofóbicas e racistas, são reconhecidas com equidade e redesenha os poderes dos saberes e a razão não mais tem espaço nas novas ordens dos discursos.

Outras vontades de verdades são expressas e as travestilidades produzem discursos, válidos, que ecoam vozes, até então, excluídas, violentadas, mas que a cada dia toma corpo, nos corpos, nas negociações das relações humanas.

Estas novas expressões de gêneros são pistas reais de como a sociedade é muito mais plural do que imaginamos e suas possibilidades tendem-se a alargarem os universos identitários para garantir todas as possibilidades de vidas, com suas potências inimagináveis, que, para as travestis disparam possíveis gêneros nômades, não fixos, não totalizados, não universais. Corroborando com um dos jargões do ativismo trans no Brasil, em sua disposição geopolítica diante da transfobia, 'quando uma travesti cai, mil se levantam'.

\section{Referências}

BRETON, D. Le. Antropologia do corpo e modernidade. Tradução de Fábio do Santos Creder Lopes. $3^{\mathrm{a}}$ ed. Petrópolis: Vozes, 2013

BUTLER, J. Corpos que pesam: sobre os limites discursivos do "sexo". In: LOURO, G. L. O corpo Educado: pedagogias da sexualidade. Belo 
O que Pode (n)um Corpo, o que Cabe Nele - Sabemos o que é um Corpo

Travesti?

Horizonte: Autêntica, 1999.

BUTLER, J. Problemas de gênero. Rio de Janeiro: Civilização Brasileira, 2003.

Quadros de guerra: quando a vida é passível de luto. Rio de Janeiro: Civilização Brasileira, 2015.

DELEUZE, G. Nietzsche e a Filosofia. Tradução de Ruth Joffily e Edmundo Fernandes Dias. Rio de Janeiro: Editora Rio, 1976

DELEUZE, G.; GUATTARI, F. Mil platôs: capitalismo e esquizofrenia. vol. 1; Tradução de Aurélio Guerra Neto e Célia Pinto Costa. Rio de janeiro: Editora 34, 1995.

ESCÓSSIA, L.; TEDESCO, S. O coletivo de forças como plano de experiência cartográfica. In: PASSOS, E.; KASTRUP, V.; ESCÓSSIA, L. (Org.). Pistas do método da cartografia: pesquisa-intervenção e produção de subjetividade. Porto Alegre: Sulina, 2009. p. 92-108.

FOUCAULT, M. Vigiar e punir. 21ª ed. Petrópolis: Vozes, 1984.

A ordem do discurso. São Paulo: Loyola, 1996.

Sobre a História da Sexualidade. In: . Microfísica do Poder. Rio de Janeiro: Graal, 2000.

GODOY, A. A menor das ecologias. São Paulo: Editora da Universidade de São Paulo, 2008.

HARAWAY, D. Ciencia, cyborgs y mujeres: la reinvención de la naturaleza. Ediciones Cátedra. Universitat de València - Instituto de la mujer. Madrid, 1995.

. "Gênero" para um dicionário marxista. Tradução de Mariza Corrêa. Cadernos Pagu, n. 22, p.201-246. 2004.

Saberes localizados: a questão da ciência para o feminismo e o privilégio da perspectiva parcial. Cadernos pagu, n. 5, p. 7-41. 2009.

KASTRUP, V.; PASSOS, E. Cartografar é traçar um plano Comum. Fractal, Rev. Psicol., v. 25, n. 2, p. 263-280, Maio/Ago. 2013.

PELBART, P. A comunidade dos sem comunidade. In: ensaios de biopolítica. São Paulo: Iluminuras, 2003. p. 28-41.'

Vida capital:

PRECIADO, B. Manifesto contrassexual: práticas subversivas de identidade sexual. Tradução de Maria Paula Gurgel Ribeiro. São Paulo: N-1 Edições, 
O que Pode (n)um Corpo, o que Cabe Nele - Sabemos o que é um Corpo

Travesti?

2014.

ROLNIK, S. Cartografia sentimental: transformações contemporâneas do desejo. $2^{\mathrm{a}}$ ed. Porto Alegre: Sulina Editora da UFRGS, 2014.

SADE, C.; KASTRUP, V. Atenção a si: da auto-observação à autoprodução. Estudos de Psicologia, v. 16, n. 2, p. 139-146, maio-ago. 2011.

SILVA, J. Geografias subversivas: discursos sobre espaço, gênero e sexualidades. Ponta Grossa: Todapalavra, 2009. 